\title{
Dopaminergic control of ADAMTS2 expression through CAMP/CREB and ERK: molecular effects of antipsychotics
}

Fulgencio Ruso-Julve (10 1,2,3, Ana Pombero ${ }^{3,4}$, Fuencisla Pilar-Cuéllar ${ }^{3,5,6}$, Nuria García-Díaz (2,7, Raquel Garcia-Lopez ${ }^{3,4}$, María Juncal-Ruiz 3,8, Elena Castro 3,5,6, Álvaro Díaz,5,6, Javier Vazquez-Bourgón 1,3, Agustín García-Blanco (1) ${ }^{2,7}$, Emilio Garro-Martinez ${ }^{3,5,6}$, Helena Pisonero 2,7, Alicia Estirado ${ }^{3,4}$, Rosa Ayesa-Arriola 1,3, Juan López-Giménez' Federico Mayor Jr. 10,11, Elsa Valdizán 3,5,6, Javier Meana $\mathbb{1}^{3,12}$, Javier Gonzalez-Maeso ${ }^{13}$, Salvador Martínez 3,4, José Pedro Vaqué 2,7 $^{2}$ and Benedicto Crespo-Facorro (1) $1,3,14$

\begin{abstract}
A better understanding of the molecular mechanisms that participate in the development and clinical manifestations of schizophrenia can lead to improve our ability to diagnose and treat this disease. Previous data strongly associated the levels of deregulated ADAMTS2 expression in peripheral blood mononuclear cells (PBMCs) from patients at first episode of psychosis (up) as well as in clinical responders to treatment with antipsychotic drugs (down). In this current work, we performed an independent validation of such data and studied the mechanisms implicated in the control of ADAMTS2 gene expression. Using a new cohort of drug-naïve schizophrenia patients with clinical follow-up, we confirmed that the expression of ADAMTS2 was highly upregulated in PBMCs at the onset (drug-naïve patients) and downregulated, in clinical responders, after treatment with antipsychotics. Mechanistically, ADAMTS2 expression was activated by dopaminergic signalling ( $\mathrm{D}_{1}$-class receptors) and downstream by CAMP/CREB and mitogen-activated protein kinase (MAPK)/ERK signalling. Incubation with antipsychotic drugs and selective PKA and MEK inhibitors abrogated $\mathrm{D}_{1}$-mediated activation of ADAMTS2 in neuronal-like cells. Thus, $\mathrm{D}_{1}$ receptors signalling towards CREB activation might participate in the onset and clinical responses to therapy in schizophrenia patients, by controlling ADAMTS2 expression and activity. The unbiased investigation of molecular mechanisms triggered by antipsychotic drugs may provide a new landscape of novel targets potentially associated with clinical efficacy.
\end{abstract}

\section{Introduction}

Antipsychotic drugs (APDs) remain the standard pharmacological treatment for schizophrenia (SCZ) and psychotic disorders, mainly by targeting dopamine neurotransmission (primarily $\mathrm{D}_{2}$ receptors) ${ }^{1-3}$. APDs can be

\footnotetext{
Correspondence: José Pedro Vaqué (jose.vaque@unican.es) or

Benedicto Crespo-Facorro (crespob@unican.es)

'Department of Psychiatry, University Hospital Marqués de Valdecilla-IDIVAL,

Santander 39011 Cantabria, Spain

2Department of Molecular Biology, School of Medicine, University of Cantabria,

Santander 39011 Cantabria, Spain

Full list of author information is available at the end of the article.

These authors contributed equally: José Pedro Vaqué, Benedicto Crespo-Facorro
}

classified into typical (i.e., haloperidol) and atypical (i.e., aripiprazole, risperidone or clozapine), the latter prescribed as first-line drugs and/or in refractory patients ${ }^{4}$. Despite the effectiveness of APDs in the clinical realm, there is a marked disparity among patients with respect to symptoms, responses and side effects ${ }^{5,6}$. Whereas $50-60 \%$ of patients achieve an optimal degree of clinical improvement of positive symptoms, little to no improvement of negative symptoms or cognitive deficits is common $^{5}$. Overall, estimates suggest that one-fifth to one-half of patients have treatment-resistant SCZ and about $30-60 \%$ of these respond to clozapine ${ }^{6-8}$. These

\section{(c) The Author(s) 2019}

(c) (i) Open Access This article is licensed under a Creative Commons Attribution 4.0 International License, which permits use, sharing, adaptation, distribution and reproduction c. in any medium or format, as long as you give appropriate credit to the original author(s) and the source, provide a link to the Creative Commons license, and indicate if changes were made. The images or other third party material in this article are included in the article's Creative Commons license, unless indicated otherwise in a credit line to the material. If material is not included in the article's Creative Commons license and your intended use is not permitted by statutory regulation or exceeds the permitted use, you will need to obtain permission directly from the copyright holder. To view a copy of this license, visit http://creativecommons.org/licenses/by/4.0/. 
evidences suggest that although $\mathrm{D}_{2}$ receptors is a direct target for all drugs used to treating SCZ, its blockade may not tackle the primary biological anomaly in a significant percentage of patients ${ }^{9}$. In this respect, the combined $D_{1}$ and $D_{2}$ receptors antagonism has been proposed to have synergic effects, which could account for the atypical clinical effectiveness of clozapine ${ }^{10}$. From a molecular perspective, the effects of APDs may also include the modulation of $\mathrm{D}_{2}$ receptor-independent mechanisms through indirect effects, such as, e.g., those related to other metabotropic receptors implicated in the control cAMP-dependent signalling ${ }^{11}$ and/or those related with receptor-biased agonism ${ }^{4,12}$. Downstream of cAMP, the activation of protein kinase A (PKA) promotes phosphorylation of DARPP-32 (a cytosolic protein), which has been associated with the pathophysiology of $\mathrm{SCZ}^{13,14}$. In addition, the glutamate hypothesis of SCZ led to explore its potential clinical application as targets for therapy ${ }^{15}$. The investigation of the mechanisms downstream of the receptors targeted by APDs will certainly guide to finding out new explanations for pathophysiological mechanisms and novel approaches for therapy ${ }^{4}$.

A new paradigm has emerged based on the investigation of transcriptional patterns associated with clinical responses in SCZ, raising the likelihood of revealing unknown molecular mechanisms associated with antipsychotic action that may be crucial in accomplishing optimal clinical responses ${ }^{16,17}$. Using an unbiased transcriptome approach, we have previously described a set of genes that are differentially expressed at the onset of $\mathrm{SCZ}^{16}$. In addition to this, we also showed significant differential gene expression elicited after a 3-month APD treatment in responder patients ${ }^{17}$. Among the abovementioned results, ADAMTS2 was the highest upregulated gene in SCZ patients at the onset of the disease and also was the most significant downregulated gene, back to 'healthy levels', in responder patients to treatment with APDs. The observation that the expression of ADAMTS2 can be modulated by APDs and its association with clinical response, makes it an appealing candidate to investigate its interface with illness pathology and clinical efficacy ${ }^{17}$.

In the present work we initially performed an independent validation using a new cohort of drug-naïve nonaffective psychosis patients. We confirmed that ADAMTS2 expression was significatively overexpressed at diagnosis, and that treatment with APDs reduced their expression levels back to 'healthy' values, which, in turn, was associated with clinical responses (positive symptoms). However, the molecular or cellular mechanisms exerted by APDs to regulate ADAMTS2 expression are unknown. Following a bottom-up strategy starting from the transcriptional data obtained in SCZ cases and taking advantage of neuronal-like cells towards the identification of membrane receptors and the intracellular mechanism controlled by them, we herein provide new evidence that ADAMTS2 expression is regulated by dopaminergic signalling cascade $\left(D_{1}\right.$-class receptors) through ERK and cAMP/cAMP response element-binding protein (CREB) activities.

\section{Materials and methods \\ Human samples and study setting}

Human samples for this study were obtained from an ongoing epidemiological and 3-year longitudinal intervention programme of first-episode psychosis (PAFIP) conducted at the University Hospital Marques de Valdecilla (Cantabria, Spain) and biological samples were provided by the IDIVAL biobank. The study was approved by the Cantabria Ethics Institutional Review Board, conforming to international standards for research ethics. Patients meeting inclusion criteria and their families provided written informed consent to be included in the PAFIP.

A new independent set of 30 APD-naïve, first-episode non-affective individuals and 10 healthy individuals (without a history of neuropsychiatric disorders) were used to validate gene expression profiles related to clinical response (Table 1 ).

Briefly, all patients underwent a head-to-head risperidone and aripiprazole randomized (simple randomization procedure), flexible-dose, open-label study (EudraCT number 2013-005399-16). More detailed information about PAFIP and treatment protocol has been published elsewhere ${ }^{17,18}$ and also is briefly available in Supplementary Information.

\section{RNA extraction}

Peripheral blood from patients and controls was extracted using the TempusTM Blood RNA Tube (Applied Biosystems, UK). Peripheral blood mononuclear cell (PBMC) isolation was performed using a Ficoll-Paque Premium reagent (Sigma) and total mRNA isolation using a TempusTM Spin RNA Isolation Kit (Invitrogen, CA, USA), following the manufacturer's instructions. RNA Integrity Number (RIN) was characterized with a Bioanalyzer (Agilent Technologies) and samples with a RIN > 8 were selected. Total mRNA from culture cells was extracted using Trizol reagent (Invitrogen) and its concentration was determined using a Nanodrop 2000 spectrophotometer (Thermo Scientific, IL, USA).

\section{RT-PCR and quantitative PCR}

cDNA synthesis was performed using the SuperScript IV Reverse Transcriptase (Invitrogen). cDNA was amplified using the Power SYBR $^{\mathrm{TM}}$ Green PCR Master Mix (Applied Biosystems) in a 7300 Fast Real-Time PCR System (Applied Biosystems). Specific oligos for human 
Table 1 Psychopathological characteristics at baseline, at 3 months and clinical changes during the follow-up period. Comparison between aripiprazole and risperidone.

\begin{tabular}{|c|c|c|c|c|c|c|c|c|c|c|}
\hline & \multicolumn{2}{|c|}{ Total $(N=30)$} & \multirow[t]{2}{*}{ Statistics } & \multirow[t]{2}{*}{$p$} & \multicolumn{2}{|c|}{$\begin{array}{l}\text { Aripiprazole } \\
(n=16)\end{array}$} & \multicolumn{2}{|c|}{$\begin{array}{l}\text { Risperidone } \\
(n=14)\end{array}$} & \multirow[t]{2}{*}{ Statistics } & \multirow[t]{2}{*}{$p$} \\
\hline & Mean & SD & & & Mean & SD & Mean & SD & & \\
\hline \multicolumn{11}{|l|}{ CGI } \\
\hline Baseline & 6.5 & 0.6 & & & 6.56 & 0.51 & 6.43 & 0.65 & $t=0.63^{c}$ & 0.532 \\
\hline 3 Months & 1.8 & 1.2 & & & 1.63 & 1.20 & 2.00 & 1.24 & & \\
\hline 3-Month change from baseline & -4.7 & 1.2 & $z=4.83^{\mathrm{a}}$ & 0.000 & -4.90 & 0.30 & -4.47 & 0.33 & $F=0.96^{d}$ & 0.336 \\
\hline \multicolumn{11}{|l|}{ YMRS } \\
\hline Baseline & 13.8 & 6.2 & & & 14.25 & 7.24 & 13.29 & 5.01 & $t=0.42^{c}$ & 0.679 \\
\hline 3 Months & 1.2 & 2.3 & & & 1.56 & 2.63 & 0.79 & 1.93 & & \\
\hline 3-Month change from baseline & -12.6 & 6.5 & $z=4.78^{a}$ & 0.000 & -12.25 & 0.59 & -13.00 & 0.63 & $F=0.75^{d}$ & 0.394 \\
\hline \multicolumn{11}{|l|}{ CDSS } \\
\hline Baseline & 1.5 & 3.0 & & & 2.06 & 3.82 & 0.86 & 1.75 & $t=1.08^{c}$ & 0.288 \\
\hline 3 Months & 1.2 & 2.3 & & & 1.19 & 2.34 & 1.14 & 2.25 & & \\
\hline 3-Month change from baseline & -0.3 & 3.7 & $z=0.35^{\mathrm{a}}$ & 0.724 & -0.34 & 0.59 & -0.32 & 0.63 & $F=0.00^{d}$ & 0.985 \\
\hline \multicolumn{11}{|l|}{ BPRS } \\
\hline Baseline & 70.3 & 15.0 & & & 69.06 & 16.08 & 71.85 & 13.95 & $t=-0.49^{c}$ & 0.627 \\
\hline 3 Months & 29.9 & 7.1 & & & 29.06 & 7.07 & 30.92 & 7.48 & & \\
\hline 3-Month change from baseline & -40.4 & 15.2 & $t=14.32^{b}$ & 0.000 & -41.13 & 1.81 & -39.53 & 2.01 & $F=0.35^{d}$ & 0.561 \\
\hline \multicolumn{11}{|l|}{ SAPS } \\
\hline Baseline & 15.9 & 4.2 & & & 15.63 & 3.50 & 16.07 & 4.94 & $t=-0.29^{c}$ & 0.775 \\
\hline 3 Months & 0.6 & 1.7 & & & 0.69 & 1.89 & 0.71 & 1.49 & & \\
\hline 3-Month change from baseline & -15.4 & 4.3 & $t=19.28^{\mathrm{b}}$ & 0.000 & -15.14 & 0.44 & -15.12 & 0.47 & $F=0.00^{d}$ & 0.975 \\
\hline \multicolumn{11}{|l|}{ SANS } \\
\hline Baseline & 4.8 & 6.9 & & & 3.47 & 6.56 & 5.93 & 7.43 & $t=-0.95^{c}$ & 0.352 \\
\hline 3 Months & 3.9 & 6.6 & & & 4.00 & 6.47 & 4.93 & 7.04 & & \\
\hline 3-Month change from baseline & -0.9 & 5.6 & $z=1.14^{\mathrm{a}}$ & 0.255 & -0.07 & 1.54 & -0.36 & 1.59 & $F=0.02^{d}$ & 0.899 \\
\hline
\end{tabular}

BPRS Brief Psychiatric Rating Scale, CDSS Calgary Depression Rating Scale for Schizophrenia, CGI Clinical Global Impression, SANS Scale for the Assessment of Negative Symptoms, SAPS Scale for the Assessment of Positive Symptoms, YMRS Young Mania Rating Scale

Wilcoxon matched-pairs signed-rank test

${ }^{\mathrm{b}}$ Paired Student's t-test

'Comparison between aripiprazole and risperidone at baseline; unpaired Student's $t$-test

${ }^{d}$ Comparison between aripiprazole and risperidone following the antipsychotic treatment, using the total score of the clinical scales at baseline as covariate; analysis of covariance (ANCOVA)

ADAMTS2, CREB1, and C-FOS were designed using Primer-Blast (NCBI; see sequences in Supplementary Table S1). ACTB expression was used to normalize values. Gene expression changes were determined using $2^{(-\Delta \Delta C t)}$ formula. A melting curve was generated for every run to confirm assay specificity.

\section{Cell culture and treatments}

Human neuroblastoma (SK-N-SH, ATCC HTB-11) and 293T (ATCC CRL-3216) cells were obtained from the American Type Cell Collection (Rockville, MD). Cells were cultured in modified Eagle's medium and Dulbecco's Modified Eagle's Medium, respectively (Corning, VA, USA). Culture medium was supplemented with $10 \%$ dialysed fetal bovine serum (dFBS; HyClone, UT, USA), glucose, L-glutamine, streptomycin sulphate and potassium penicillin (10,000 U/L) (Lonza, Belgium).

\section{Drugs and pharmacological agents}

Aripiprazole, clozapine, haloperidol hydrochloride, H89 dihydrochloride, L 741,626, MDL 100907, paliperidone, risperidone, SKF 83822, SCH 39166, TCB-2, WAY 
100635, 7-OH-DPAT and 8-OH-DPAT were purchased from Tocris Bioscience (Spain). Forskolin and selumetinib (AZD6244) were purchased from Selleckchem (Spain). Cholera toxin (CTX), pertussis toxin (PTX) and 12-Otetradecanoylphorbol-13-acetate (TPA) were purchased from Sigma-Aldrich (MO, USA). YM-254890 was purchased from Adipogen Life Sciences (CA, USA). All were dissolved in dimethyl sulfoxide, except CTX and WAY 100635 that were dissolved in water.

\section{Luciferase report assays}

Luciferase report assays were performed by transfection with $0.5 \mu \mathrm{g}$ DNA of the following plasmids mix (ratio 3:1): pGL4.29[luc2P/CRE/Hygro] containing firefly luciferase reporter, alongside pRL-Null containing Renilla luciferase used as control (Promega, WI, USA). Cells were transfected with Lipofectamine LTX with PLUS reagents (Invitrogen) in transient conditions. Firefly and Renilla levels were detected using Dual-Luciferase Reporter Assay System kit and quantified using a GloMax-Multi apparatus (Promega).

\section{Western blotting}

Cells were starved overnight before treatment. Whole cell lysates were obtained using RIPA buffer (Sigma) supplemented with phosphatase and protease inhibitors (Roche, Germany). Protein expression was analysed by western blotting as described previously ${ }^{19}$. Briefly, antibodies used were as follows: phospho-CREB, CREB, phospho-ERK1/2, ERK1/2, phospho-p38, p38, and phospho-PKA substrates (Cell Signaling, MA, USA), and $\beta$-Tubulin (Santa Cruz Biotechnology). Fluorophore conjugate antibodies were obtained from Invitrogen. Signals were visualized and recorded with an Odyssey Infrared Imaging scanner (LI-COR Biosciences, NE, USA). Immunoblot densitometry analysis on every band was calculated using Image Studio Software (LI-COR Biosciences). Phosphorylation and total protein densitometry values were normalized to $\beta$-Tubulin signal.

\section{CREB knocked down reagents and procedures}

ShCREB1-inducible SK-N-SH cells were generated by lentiviral infection of SK-N-SH cells with SMARTvector carrying tGFP and human inducible CREB1 short hairpin RNA (shRNA) mCMV constructs or non-target control shRNA (Dharmacon, CO, USA). Lentiviral particles were produced by co-transfection of $293 \mathrm{~T}$ cells using TransLentiviral shRNA Packaging System (Dharmacon), according to the manufacturer's protocol. Cells were incubated with doxycycline $(1 \mu \mathrm{g} / \mathrm{ml})$ (Sigma) for $72 \mathrm{~h}$ to induce green fluorescent protein and shRNA expression. SK-N-SH cells expressing stable shCREB1 constructs were generated by direct transfection by Lipofectamine LTX with PLUS reagent (Invitrogen) using pGFP-V-RS-
CREB1 shRNA expression vectors or scrambled control (Origene, MD, USA). Transfected cells were selected with puromycin $(1 \mu \mathrm{g} / \mathrm{mL})$ at least 7 days.

\section{Statistical analyses}

Kolmogorov-Smirnov test and Levene test were used to test normality and equality of variances, respectively.

For patients' studies, to ensure group comparability between healthy volunteers and patients, sociodemographic and clinical characteristics at baseline were tested by unpaired Student's $t$-test or one-way analysis of variance (ANOVA) for continuous variables as necessary, and by Fisher's exact test for qualitative variables (Table 1 and Supplementary Table S2).

Wilcoxon's signed-rank test for independent data was used to compare the ADAMTS2 mRNA expression level among healthy volunteers and drug-naïve patients at baseline. Wilcoxon's matched-pairs signed-rank test for paired data was performed to compare the change in the mRNA expression level from baseline to 3 months following the antipsychotic treatment $(\alpha=0.05)$. STATA 15.1 was used for statistical analysis.

For in vitro studies, unless otherwise specified, all experiments were independent and numerical data were summarized as the mean \pm SEM using GraphPad Prism6 software. Each global mean was compared using unpaired Student's $t$-test (two tailed; $\alpha=0.05$ ) or one-way ANOVA followed by post-hoc test where appropriated, as described in each figure legend.

\section{Results}

\section{ADAMTS2 expression is controlled by APD treatment in SCZ patients}

To better evaluate the mechanistic effects of atypical APDs in SCZ patients, we prepared and studied a new cohort of 30 drug-naïve SCZ patients with baseline quantitative data (sociodemographic and clinical characteristics) and clinical follow-up data, after 3 months of treatment with APDs (Table 1). We found significant within-subject changes between baseline data and after 3 months of treatment in both risperidone and aripiprazole groups. These changes were observed in CGI (Clinical Global Impression, $p<0.000$ ), YMRS (Young Mania Rating Scale, $p<0.000$ ), BPRS (Brief Psychiatric Rating Scale, $p<0.000$ ) and SAPS (Scale for the Assessment of Positive Symptoms, $p<0.000$ ) total scores. However, as it is shown in Table 1, no differences were found in total scores of the clinical scales when the two APD groups were compared at baseline and after 3 months of treatment.

To analyse transcriptomic changes, we obtained PBMCs isolated from blood samples from SCZ patients, which were obtained at the first episode of psychosis (onset) and after a 3-month period of treatment with APDs. In this 


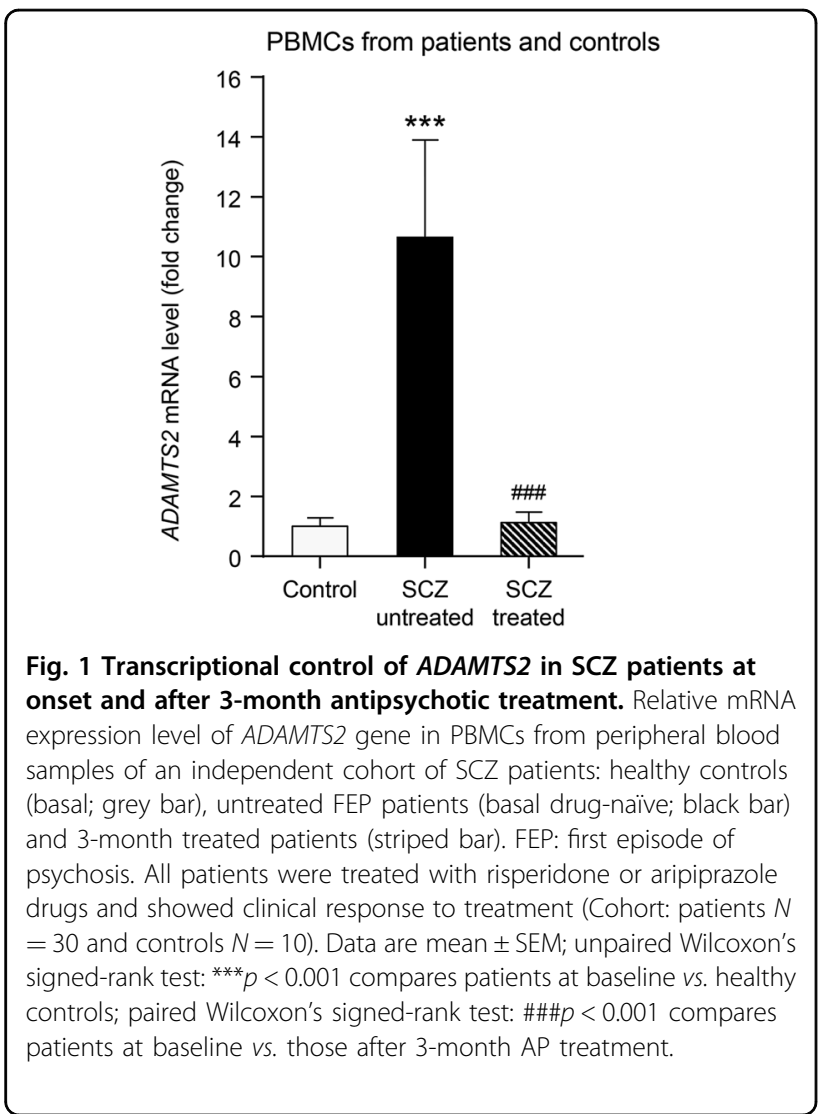

context, using quantitative reverse transcriptase PCR (RTqPCR), we performed an independent validation of transcriptional changes by focusing on ADAMTS2. Thus, we confirmed $A D A M T S 2$ as a significant gene that was highly overexpressed at the onset, with respect to healthy controls, and downregulated by APDs after 3 months of treatment (Fig. 1).

\section{Dynamic control of ADAMTS2 transcription by APDs in neuronal-like cells}

To gain mechanistic insight into the transcriptional control of $A D A M T S 2$, we analysed the effects of APDs in SK-N-SH cells using dFBS. No significant differences in ADAMTS2 expression were observed when dFBS was not present in the culture medium (data not shown). These cells express cell surface receptors that are targets of APDs (i.e., $\mathrm{D}_{1}, \mathrm{D}_{2}, 5-\mathrm{HT}_{1 \mathrm{~A}}$ and $5-\mathrm{HT}_{2 \mathrm{~A}}$ receptors) as well as detectable basal expression of ADAMTS2 mRNA. Our data showed that incubation with APDs in these cells induced dynamic changes in ADAMTS2 mRNA expression along time. Incubation with atypical APDs such as paliperidone, aripiprazole (Fig. 2) and risperidone (Supplementary Fig. S1), provoked a dynamic inhibition of ADAMTS2 basal mRNA expression in these cells with fast $(<1 \mathrm{~h})$ but transitory responses. Interestingly, clozapine (atypical APD) and haloperidol (typical APD) induced a
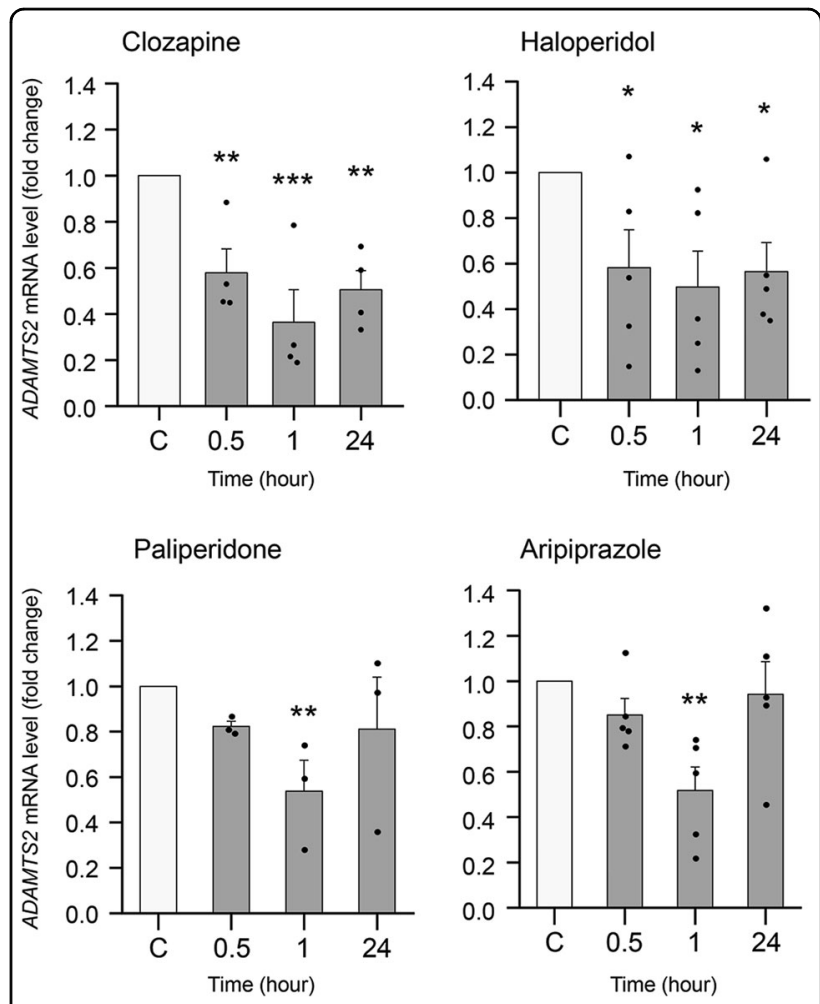

Fig. 2 Transcriptional control of ADAMTS2 using antipsychotic drugs. Relative ADAMTS2 mRNA expression level in SK-N-SH cells incubated with clozapine $(1 \mu \mathrm{M})(N=4)$, haloperidol $(1 \mu \mathrm{M})(N=5)$, paliperidone $(1 \mu \mathrm{M})(N=3)$ and aripiprazole $(1 \mu \mathrm{M})(N=5)$ for the indicated times. Data are mean \pm SEM; one-way ANOVA for multiple comparations: ${ }^{*} p<0.05,{ }^{* *} p<0.01,{ }^{* * *} p<0.001$ shows significance with respect to control (C; vehicle, grey bars).

fast and sustained (up to $24 \mathrm{~h}$ ) inhibition of ADAMTS2 expression (Fig. 2).

\section{Neurotransmitter receptors and associated signalling pathways involved in the control of ADAMTS2 gene expression}

Using selective agonists for $\mathrm{D}_{1}, \mathrm{D}_{2}, 5-\mathrm{HT}_{1 \mathrm{~A}}$ and $5-\mathrm{HT}_{2 \mathrm{~A}}$ receptors in SK-N-SH cells, we observed that SKF 83822 (a $\mathrm{D}_{1}$-class receptor agonist) significantly triggered ADAMTS2 mRNA expression compared with the lack of effect of 7-OH-DPAT, 8-OH-DPAT and TCB-2 (agonists of $\mathrm{D}_{2}, 5-\mathrm{HT}_{1 \mathrm{~A}}$ and $5-\mathrm{HT}_{2 \mathrm{~A}}$ receptors, respectively) (Fig. 3a). In addition, using selective antagonists for these receptors, we observed that only $\mathrm{SCH} 39166$ (a $\mathrm{D}_{1}$-class receptor antagonist) significantly downregulated ADAMTS2 mRNA expression, whereas L 741,626, WAY 100635 and MDL 100907 (antagonists of $\mathrm{D}_{2}, 5-\mathrm{HT}_{1 \mathrm{~A}}$ and $5-\mathrm{HT}_{2 \mathrm{~A}}$ receptors, respectively) were devoid of this effect (Fig. 3a). Furthermore, we analysed ADAMTS2 mRNA and protein expression profiles in the brain of developing and early postnatal mice (see Supplementary Methods). Interestingly and in support of our previous results in 


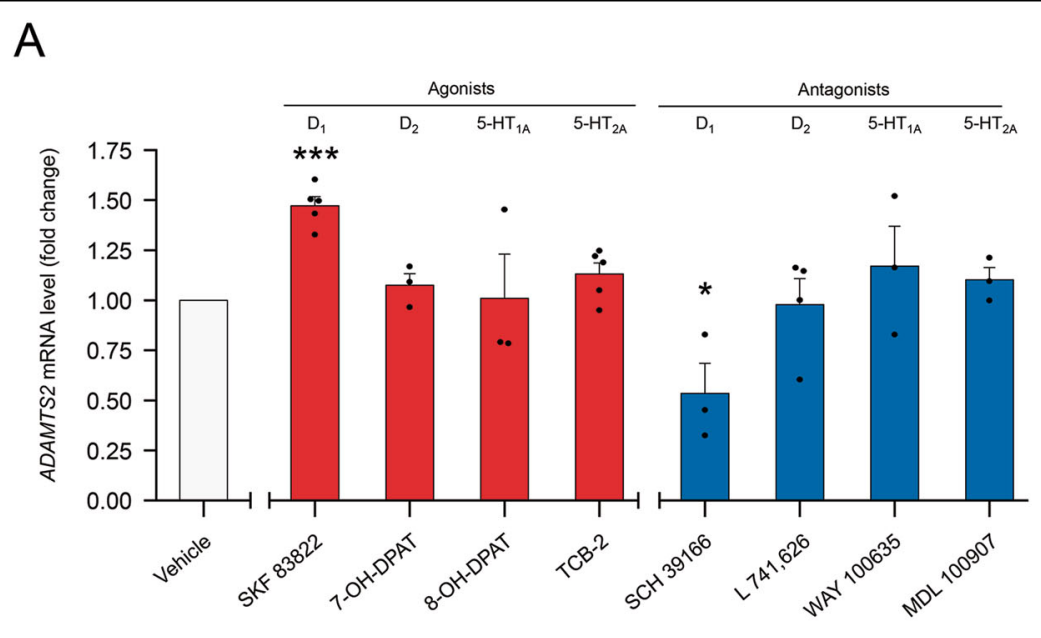

B

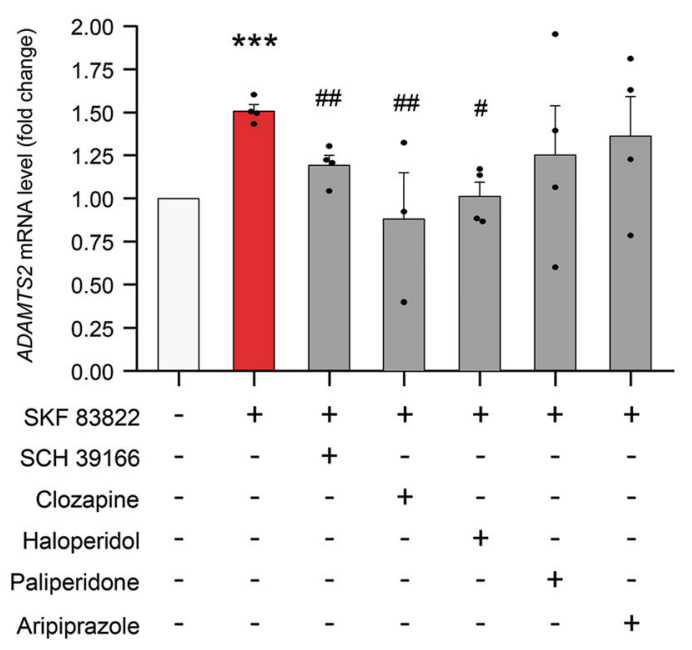

D

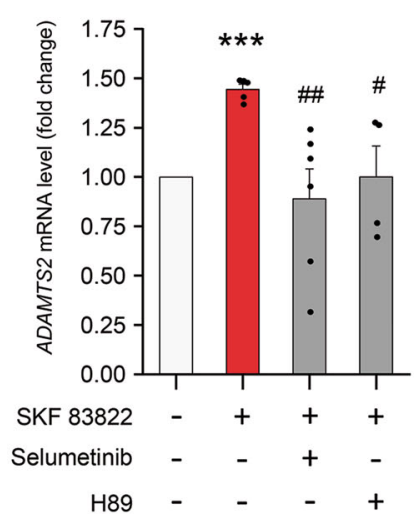

C

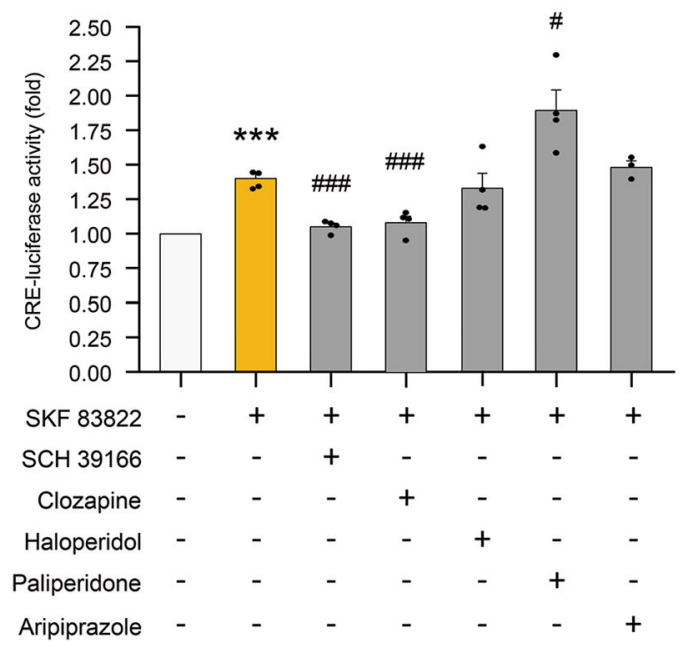

F

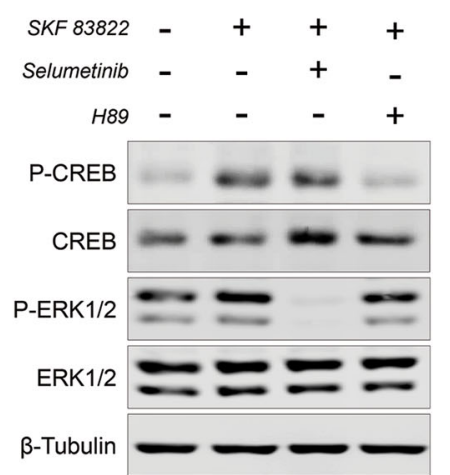

F

Fig. 3 (See legend on next page.)

E

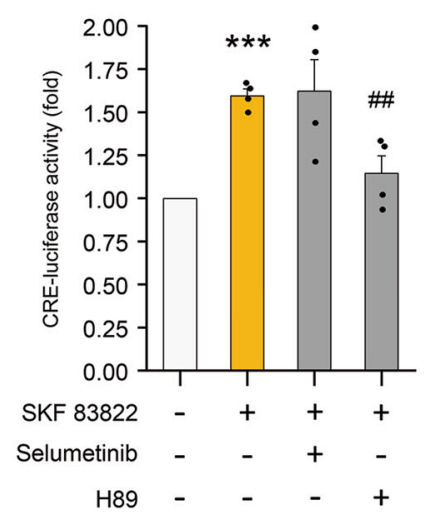


(see figure on previous page)

Fig. 3 Neurotransmitter receptors and associated signalling pathways involved in the control of ADAMTS2 gene expression. a ADAMTS2 mRNA levels by RT-qPCR in SK-N-SH cells incubated $1 \mathrm{~h}$ with the indicated selective receptor agonist (red bars): SKF $83822\left(\mathrm{D}_{1}\right.$-class receptors) $(N=5)$, 7-OH-DPAT ( $\mathrm{D}_{2}$-Class receptors) $(\mathrm{N}=3), 8-\mathrm{OH}-\mathrm{DPAT}\left(5-\mathrm{HT}_{1 \mathrm{~A}}\right.$ receptor) $(\mathrm{N}=3)$ and TCB-2 $\left(5-\mathrm{HT}_{2 \mathrm{~A} / 2 \mathrm{C}}\right.$ receptors) $(\mathrm{N}=5)$; and selective antagonist (blue bars): SCH 39165 ( $D_{1}$-class receptors) $(N=3), \mathrm{L} 741,626$ ( $\mathrm{D}_{2}$-class receptors) $(N=4), \mathrm{WAY} 100635\left(5-\mathrm{HT}_{1 \mathrm{~A}}\right.$ receptors $)(N=3)$ and MDL $100907(5-\mathrm{HT} 2 \mathrm{~A}$ receptors) $(N=3)$ (Drug concentration $1 \mu \mathrm{M})$. b ADAMTS2 mRNA levels by RT-qPCR in cells incubated for $1 \mathrm{~h}$ with SKF $83822(N=4)$ and preincubated also for 30 min with SCH $39166(N=4)$, clozapine $(N=3)$, haloperidol $(N=4)$, paliperidone $(N=4)$ or aripiprazole $(N=4)(D r u g$ concentration $1 \mu \mathrm{M})$. c CREB activity in cells transfected with CRE-Luc alongside pRL-Null: cells were pre-incubated for $1 \mathrm{~h}$ with the indicated APDs and then, incubated for $24 \mathrm{~h}$ with SKF $82833(10 \mu \mathrm{M})(\mathrm{N}=4)$. $\mathbf{d}$ ADAMTS2 mRNA levels by RT-qPCR: SK-N-SH cells were pre-incubated for 30 min with MAPK/ERK and CAMP-PKA inhibitors (selumetinib $1 \mu \mathrm{MN}=6$ and $\mathrm{H} 8910 \mu \mathrm{MN}=4$, respectively) and then, incubated for $1 \mathrm{~h}$ with SKF $82833(1 \mu \mathrm{M})$ $(N=5)$. e CREB activity in cells transfected with CRE-Luc alongside pRL-Null $(N=4)$ : SK-N-SH cells were pre-incubated for $1 \mathrm{~h}$ with the indicated inhibitors and then incubated for $24 \mathrm{~h}$ with SKF $82833(10 \mu \mathrm{M})$. $\mathbf{f}$ Western blottings showing relative phosphorylation levels of CREB and ERK1/2: SK-NSH cells were pre-incubated for $1 \mathrm{~h}$ with the indicated inhibitors and then incubated for 15 min with SKF $82833(1 \mu \mathrm{M})(N=3)$. Blots are representative images of each western-blot. Data are mean \pm SEM; Student's $t$-test: ${ }^{*} p<0.05$ and ${ }^{* * *} p<0.001$ vs. control condition (vehicle), and \#p $<$ $0.05, \# \# p<0.01, \# \# \# p<0.001$ vs. SKF 83822 condition.

cells, ADAMTS2 was specifically localized in brain regions that are part of the mesolimbic and mesocortical dopamine systems (Supplementary Fig. S2).

Next, we studied whether treatment with APDs could modulate ADAMTS2 gene expression activated downstream of the $D_{1}$ receptor. Our results show that haloperidol and clozapine could significantly block SKF 83822mediated transcriptional activation of ADAMTS2. As expected, $\mathrm{SCH} 39166$, a selective $\mathrm{D}_{1}$ receptor antagonist, also prevented $\mathrm{D}_{1}$ receptor-mediated activation of ADAMTS2 (Fig. 3b). In addition, the reduction in ADAMTS2 expression induced by clozapine was prevented by $\mathrm{L}$ 741,626 and MDL 100907 (a $\mathrm{D}_{2}$ and 5- $\mathrm{HT}_{2 \mathrm{~A}}$ receptor antagonists, respectively) (Supplementary Fig. S3).

As $D_{1}$ receptors are known to signal through $G_{\alpha s}$, we sought to confirm its role at controlling ADAMTS2 expression in our system, alongside $G_{\alpha i}$ and $G_{\alpha q}$. For this purpose, we incubated SK-N-SH cells with CTX ( $G_{\alpha s}$ activator), PTX ( $G_{\alpha i}$ inhibitor) and YM-254890 (a specific $G_{\alpha q}$ inhibitor) ${ }^{20}$, before activating $D_{1}$ receptors with SKF 83822. The activation of $G_{\alpha s}$ (Supplementary Fig. S4A) and the inhibition of $\mathrm{G}_{\alpha \mathrm{i}}$ (Supplementary Fig. S4B) per se significantly upregulated $A D A M T S 2$ expression. Moreover, the inhibition of $\mathrm{G}_{\mathrm{\alpha i}}$ potentiated ADAMTS2 expression after $D_{1}$ receptor activation (Supplementary Fig. S4B). Finally, the inhibition of $\mathrm{G}_{\alpha q}$ did not modify the basal and the SKF 83822-mediated increase of ADAMTS2 expression (Supplementary Fig. S4C).

Incubation of neuronal-like cells with the selective $D_{1}$ receptor agonist (SKF 83822) provoked rapid phosphorylation of CREB and ERK1/2 (15 min), and no changes in p38 (Supplementary Fig. S4D-F). In addition, rapid phosphorylation of PKA substrates was detected in response to SKF 83822 (Supplementary Fig. S4G). To evaluate CREB-dependent transcriptional activity in neuronal-like cells, we took advantage of a CRE-luciferase reporter. We analysed if APDs could counteract the intracellular signalling activation mediated by selective SKF $83822 \mathrm{D}_{1}$-class receptor agonist. Our results (Fig. 3c) demonstrate that preincubation with clozapine, but not haloperidol, paliperidone, or aripiprazole, prevented SKF 83822-induced CREB activation using a specific reporter assay.

To evaluate the potential contribution of PKA and ERK to the activation of ADAMTS2 expression, we incubated SK-N-SH cells with SKF $83822 \mathrm{D}_{1}$ receptor agonist in combination with selective MAPK/ERK (selumetinibAZD6244) and cAMP/PKA (H89 dihydrochloride) inhibitors. Both inhibitors prevented $D_{1}$ receptor induced expression of ADAMTS2 (Fig. 3d), although only a cAMP/ PKA inhibitor abrogated CREB-dependent transcription and phosphorylation (Fig. 3e, f).

\section{Transcriptional mechanisms controlling ADAMTS2 gene expression downstream of dopamine $D_{1}$ receptors}

Our previous data suggest that there is a rapid activation of the signalling mechanisms controlling CREB activation after $D_{1}$ receptor activation that can be modulated pharmacologically. We decided to challenge the contribution of CAMP/CREB signalling to the transcriptional activation of ADAMTS2 (Fig. 4a). We initially evaluated the activation of ADAMTS2 gene expression together with that of $C$-FOS, an 'early response gene' known to be a direct transcriptional target of CREB that was used as control. Our data showed that SKF 83822 activated mRNA expression of both ADAMTS2 and CFOS. Interestingly, incubation with forskolin alone (a selective adenyl cyclase activator) was sufficient to trigger the transcription of both genes, whereas TPA (a PKC/ MAPK activator) uniquely activated C-FOS transcription.

To explore the implication of CREB in $\mathrm{D}_{1}$ receptormediated ADAMTS2 expression, we generated stable SK$\mathrm{N}-\mathrm{SH}$ cells with inducible expression of control or CREB1 shRNAs upon addition of doxycycline to the culture media. Using this approach, we reduced CREB1 mRNA and protein expression, as shown in Fig. 4b. Under these settings, SKF 83822 and forskolin failed to induce the expression of ADAMTS2 (Fig. 4c). Interestingly, SKF 
83822 did not significantly activate C-FOS expression in CREB1 knocked down cells when compared with control cells; in contrast, TPA did (Fig. 4d). A schematic representation of the signalling pathways and the molecules used in this work is illustrated in Fig. 5 for explanatory purposes. The above-mentioned results were further confirmed using SK-N-SH cells stably expressing control or CREB1 shRNAs (Supplementary Fig. S5). Mechanistically, reduced CREB expression did not impair ERK phosphorylation elicited downstream of $\mathrm{D}_{1}$ receptor activation by SKF 83822 (Fig. 4e). In this context, we also used forskolin and TPA as controls for selective activation of CREB and ERK, respectively (Fig. 4e and Supplementary Fig. S6). Thus, activation of CREB seems to play a key role in the control of ADAMTS2 gene expression downstream of $\mathrm{D}_{1}$ receptors.

\section{Discussion}

Our results revealed that treatment with APDs control ADAMTS2 expression, which is directly associated with dopaminergic signalling, primarily with the $D_{1}$-class receptors and downstream through cAMP/CREB and MAPK signalling. Interestingly, ADAMTS2 mRNA and protein were specifically found in mesolimbic and mesocortical dopaminergic regions in mice. Our data suggest that $\mathrm{D}_{1}$ receptor signalling towards CREB activation and its effects on ADAMTS2 expression may be linked to key biological mechanisms in SCZ and the clinical response to $\mathrm{APDs}^{21,22}$.

In the context of the local PAFIP programme, we collected a new cohort of 30 drug-naïve SCZ patients with associated clinical data and follow-up. Using these cases alongside 'healthy' controls, we attempted an independent validation of our previous results using a different cohort of cases ${ }^{16,17}$. In this cohort, we confirmed ADAMTS2 as a significant gene that was highly overexpressed at baseline in PBMCs from drug-naïve SCZ individuals and which returned to 'normal' levels in clinical responders treated with APDs (clinical rate scales in Table 1). Although, there is not always a direct correlation between the biomarkers obtained in peripheral blood cells and the central nervous system (CNS) samples, a previous study in a rodent model of SCZ have shown a certain parallelism between the expression in human PBMCs ${ }^{16,17}$ and mouse frontal cortex samples ${ }^{23}$. Supporting the previously mentioned data, ADAMTS2 mRNA expression was quickly downregulated by all APDs in neuronal-like cells. Moreover, whereas the activities of paliperidone, risperidone, and aripiprazole downregulating ADAMTS2 mRNA were transitory in such cells, those of clozapine and haloperidol were sustained to up to $24 \mathrm{~h}$. The molecular effects exerted by clozapine and haloperidol as compared with other APDs might deserve further investigations. In this respect, clozapine has shown superior efficacy for treatment-resistant and suicidality, as well as its apparent ability to decrease substance use in $\mathrm{SCZ}^{24}$. Thus, ADAMTS2 might play a key, and yet to be defined, mechanistic role in both the illness onset and clinical responses, regardless of the type of APD used.

There is scarce information regarding specific ADAMTS2 expression and activity in the CNS. Therefore, we analysed the expression profiles of ADAMTS 2 mRNA and protein in mice. Interestingly, these were specifically localized in brain regions that are part of the mesolimbic and mesocortical dopamine systems (i.e., the dentate gyrus in the hippocampus and the ventral tegmental area $\mathrm{e}^{21,22,25}$. At a prenatal stage (E18.5), ADAMTS2 protein was mapped in the neuropiles of anterior brain structures, anterior cingulate cortex, superficial striatum and lateral septum, where neuronal expression of dopamine $D_{1}$ and $D_{2}$ receptors was detected by in situ hybridization (http://developingmouse.brain-map.org/). The hypothesis that dopamine and dopaminergic mechanisms are essential to psychosis, and particularly to SCZ, has been one of the most enduring ideas about this disorder ${ }^{26}$. Elevated presynaptic striatal dopamine correlates most closely with the symptom dimension of psychosis and blockade of this heightened transmission leads to a resolution of symptoms for most patients ${ }^{27}$. Nonetheless, the functional association between ADAMTS2 and the dopaminergic system has not been previously established, to our best knowledge. ADAMTS2 is a member of the ADAM Metallopeptidase with Thrombospondin family ${ }^{28,29}$, with a number of targets such as the $\mathrm{N}$-propeptides of procollagens I-III, fibronectin, decorin and Dkk3 participating in extracellular matrix (ECM) organization, as well as in transforming growth factor (TGF)$\beta$ and WNT signalling ${ }^{30,31}$. Alterations in the ECM as well as TGF- $\beta$ and WNT signalling have been associated with $\mathrm{SCZ}^{32-34}$. Moreover, deregulated mRNA expression of MMPs (MMP-16, -24 and -25) and ADAMTS (ADAMTS-1, -6 and -8$)$ families of proteases have also been reported in $\mathrm{SCZ}^{35,36}$. Thus, considering ADAMTS2 expression and its associated activities in the CNS, as well as the data presented in this work, it is conceivable to speculate that it could participate in $\mathrm{SCZ}$ at different stages of the disease. In this regard, a selective $D_{1}$-class receptor agonist (SKF 83822) significantly activated $A D A M T S 2$ expression, and haloperidol and clozapine blocked this activation in neuronal-derived cells. It will be of interest, to address these appealing questions, within the next future, using SCZ and/or ADAMTS2 transgenic mice models.

$\mathrm{D}_{1}$ receptors are the most abundant dopaminergic receptor in CNS and their functional crosstalk with $\mathrm{D}_{2}$ receptor is well documented ${ }^{11,37,38}$. $D_{1}$ receptor activate adenylyl cyclase $(\mathrm{AC})$, which in turn regulate intracellular cAMP levels leading to PKA activation and CREB phosphorylation $^{39-41}$. Our data have shown that selective $D_{1}$ receptor activation upregulated ADAMTS2 expression 
A

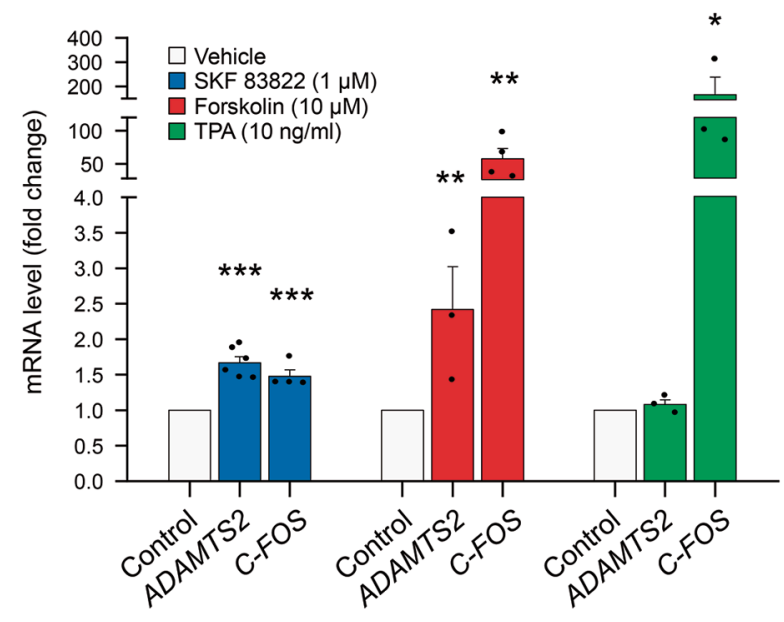

B Inducible shCREB1 (lentiviral)

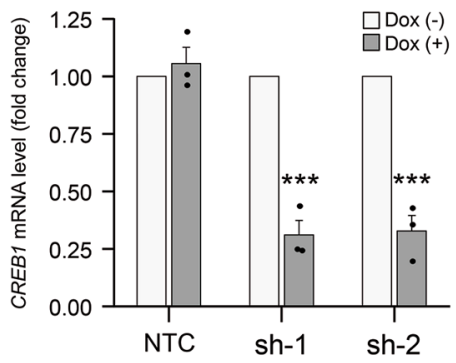

Doxycycline $(1 \mu \mathrm{g} / \mathrm{ml}) \quad-\quad+\quad+\quad+\quad$ - +

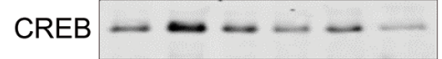

$\beta$-Tubulin -----
C

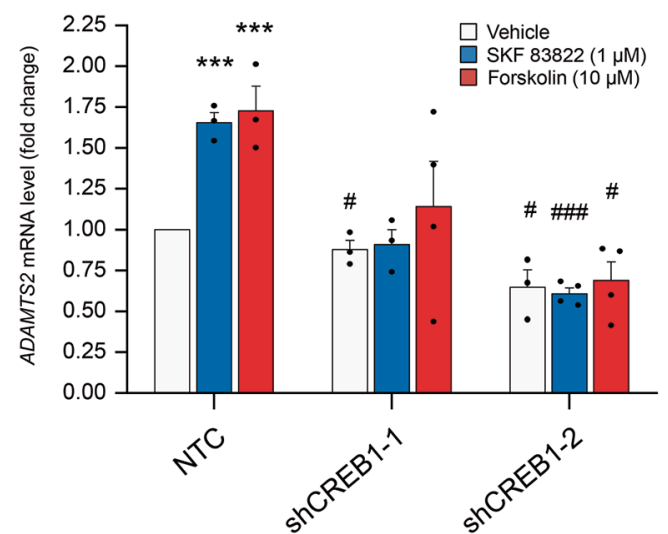

D

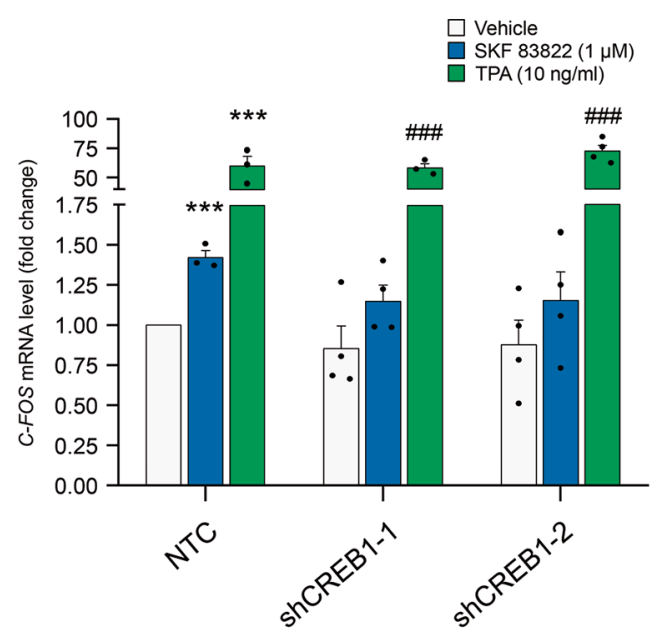

$E$

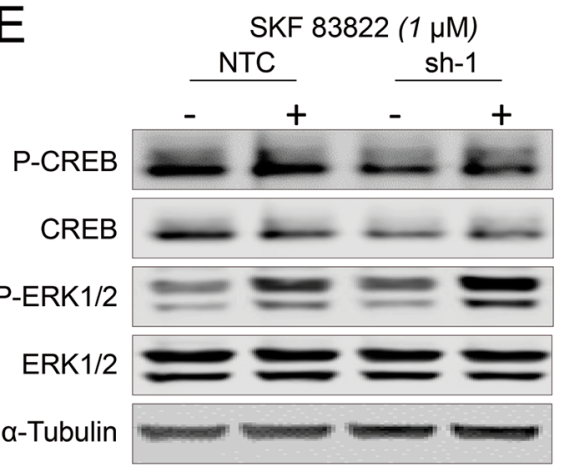

Forskolin $(10 \mu \mathrm{M})$

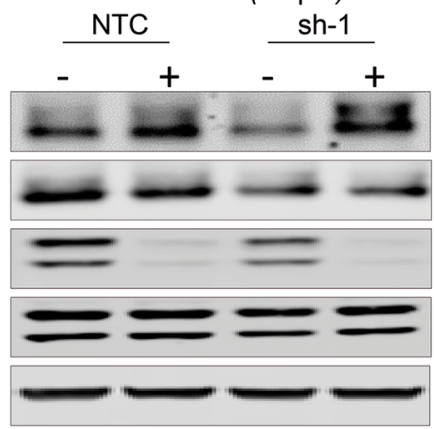

TPA $(10 \mathrm{ng} / \mathrm{ml})$

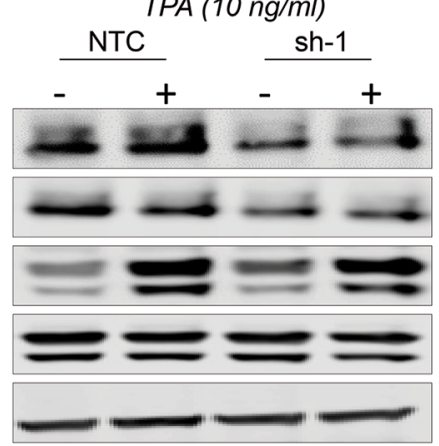

Fig. 4 Transcriptional mechanisms that control ADAMTS2 gene expression downstream of dopamine $\mathrm{D}_{1}$-class receptors. a RT-qPCR showing ADAMTS2 and C-FOS mRNA expression level in SK-N-SH cells incubated for $1 \mathrm{~h}$ with SKF $83822(1 \mu \mathrm{M}$; blue bars) $(N=6$ and $N=4$, respectively), forskolin (10 $\mu \mathrm{M}$; red bars) ( $N=3$ and $N=4$, respectively) and TPA (10 ng/ml; green bars) $(N=3)$. b CREB1 knockdown SK-N-SH cells by lentiviral inducible shRNA and GFP reporter construct (yellow bars), incubated with doxycycline $(1 \mu \mathrm{g} / \mathrm{ml})$ for $72 \mathrm{~h}$, CREB1 mRNA level (up) and CREB protein total expression (down) in non-targeted control (NTC) or shCREB1 cells $(\mathrm{N}=3)$. Inducible CREB1 Knockdown SK-N-SH cells were incubated for $1 \mathrm{~h}$ with SKF $83822(1 \mu \mathrm{M}$, blue bars), forskolin $(10 \mu \mathrm{M}$, red bars) and TPA (10 ng/ml, green bars): RT-qPCR showing ADAMTS2 (c) and C-FOS (d) mRNA expression in inducible shCREB1 or non-targeted control (NTC) cells incubated with doxycycline $(1 \mu \mathrm{g} / \mathrm{ml})$ for $72 \mathrm{~h}(\mathrm{~N}=3-4)$. e Shows western blottings using anti-phospho-CREB and anti-phospho-ERK, as well as anti-CREB and anti-ERK antibodies: inducible shCREB1 or non-targeted control (NTC) SK-N-SH cells incubated with doxycycline $(1 \mu \mathrm{g} / \mathrm{ml})$ for $72 \mathrm{~h}$ and then incubated for $15 \mathrm{~min}$ with SKF $83822(1 \mu \mathrm{M})$, forskolin $(10 \mu \mathrm{M})$ and TPA $(10 \mathrm{ng} / \mathrm{ml})(\mathrm{N}=3)$. Inducible knockdown cells were selected with puromycin $(1 \mu \mathrm{g} / \mathrm{ml})$ at least 7 days. Blots images are representative of independent

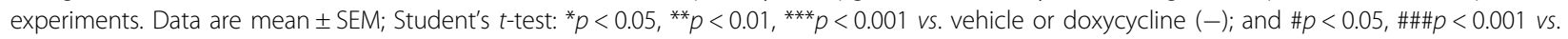
each condition in NTC cells. 


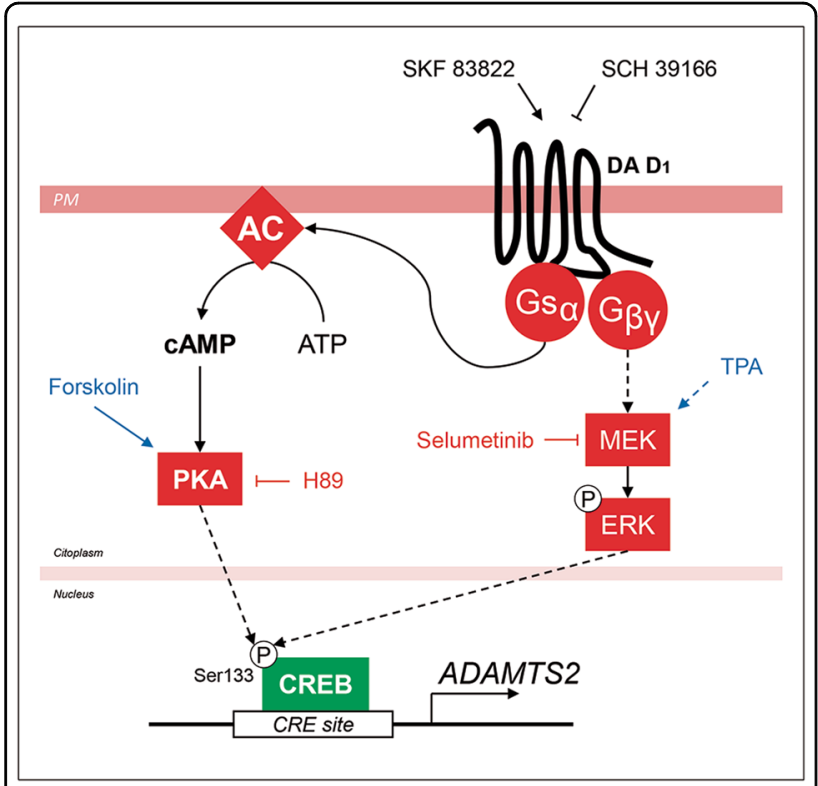

Fig. 5 Schematic representation of the mechanisms that control ADAMTS2 gene expression. Selective stimulation of $D_{1}$ receptors by SKF 83822 (selective $D_{1}$ receptor agonist) triggers the expression of ADAMTS2. Two main pathways seem to be involved: (1) $G_{a s} / A C / C A M P /$ PKA signalling and (2) MEK/ERK1/2 signalling. Downstream of $D_{1}$ both PKA and ERK can phosphorylate CREB at Ser133 and activate

transcription of ADAMTS2. Specific activators of PKA (Forskolin) and MEK (TPA) are highlighted in blue. Specific inhibitors of PKA (H89) and MEK (selumetinib) are coloured in red. DA $D_{1}$ (dopamine $D_{1}$ receptor), Gsa (G-protein a-subunit), G $\beta \gamma$ (G-protein $\beta \gamma$-subunits), AC (adenyl cyclase), PKA (protein kinase A), CRE (cyclic AMP-responsive element) site and PM (plasmatic membrane). Arrows: direct interaction, dashed arrows: indirect interaction.

alongside a rapid phosphorylation of CREB and ERK proteins, which resulted in CREB-mediated transcriptional activity as detected by using specific reporter assays (Fig. 3). In support of this and in our system, ADAMTS2 transcription was specifically triggered by activation of $D_{1}$ receptors (by SKF 83822), $\mathrm{G}_{\mathrm{\alpha s}}$ (using CTX) and AC (forskolin). Thus, it is possible that, as part of the dopaminergic activity, ADAMTS2 could act as a major cAMP/CREB effector in SCZ. Interestingly, $\mathrm{D}_{1}$ receptor-mediated CREB activation was abrogated by clozapine (Fig. 3c), providing evidence that cAMP/CREB signalling, and therefore ADAMTS2 expression, can be modulated by APDs. Our findings reveal the contribution of $\mathrm{D}_{1}$ receptors over ADAMTS2 transcription, and also indicate the participation of $\mathrm{D}_{2}$ and $5-\mathrm{HT}_{2 \mathrm{~A}}$ receptors in the effect of clozapine in the control of ADAMTS2 expression. In this regard, it has been reported that clozapine can act as a biased agonist on 5- $\mathrm{HT}_{2 \mathrm{~A}}$ receptors ${ }^{42,43}$ and/or affect the hetero-dimer $\mathrm{D}_{2} /$ $5-\mathrm{HT}_{2 \mathrm{~A}}{ }^{44}$. Moreover, disrupting cAMP/CREB and ERK signalling using selective PKA and MEK inhibitors also impaired ADAMTS2 expression and CREB activity (in this case, only when it was PKA dependent) in neuronal-like cells. Supporting these observations, recent data pointed at cAMP/CREB signalling as an important mechanism linking dopaminergic signalling with the pathophysiology of $\mathrm{SCZ}^{45}$. Moreover, incubating SK-N-SH cells with forskolin was sufficient to trigger ADAMTS2 expression that occurred alongside PKA and CREB activation. Forskolin directly activates $\mathrm{AC}$ in mammals, thereby promoting a rapid phosphorylation of CREB via PKA ${ }^{46,47}$. In addition, in CREB-knockdown cells, $D_{1}$ receptor activation failed to increase ADAMTS2 gene expression, reinforcing the idea that cAMP/CREB is an essential mechanism to control ADAMTS2 transcriptional activation.

Finally, a number of potential limitations could be considered when interpreting our data and the scope of our findings: (1) sample size in this study is rather small $(N=30)$. Noteworthy, we selected a group of patients with a first episode of non-affective psychosis, who had not previously taken APDs (not even a single dose) at the time of baseline blood test to avoid any interference with the mRNA levels. Only those individuals who gave written consent and had mRNA samples at baseline and at 3 months were eligible for this study. Therefore, all these stringent inclusion criteria limited the number of patients in this cohort. Further investigations to replicate our findings using larger and more heterogeneous groups are warranted. (2) Transcriptomic data obtained from blood samples might not resemble that of the brain. (3) ADAMTS2 protein and mRNA expression show modest but detectable levels in 'healthy' human and mouse brain samples (https://www.proteinatlas.org). Thus, it is conceivable to detect high fold increases when analysing diseased specimens, like in this case ADAMTS2 in SCZ. (4) Failure of some APDs to inhibit CREB activity and/or ADAMTS2 mRNA expression in a $\mathrm{D}_{1}$ receptor-context. Our data herein do not discard that APDs might regulate ADAMTS2 by indirect mechanisms like for example those involving $\beta$-arrestin, ERK or AKT signalling ${ }^{42,48}$.

In conclusion, we have confirmed the association between ADAMTS2 expression and SCZ disease including its potential role in the clinical efficacy of APDs. Transcription of ADAMTS2 is primarily controlled by the activity of $D_{1}$-class receptors through cAMP/CREB and MAPK signalling. The unbiased investigation of the molecular mechanisms triggered by APDs, may provide a landscape of novel targets potentially associated with improved therapeutic responses.

\section{Acknowledgements}

We are highly indebted to the participants and their families for their cooperation in this study. We also thank IDIVAL biobank (Inés Santiuste and Jana Arozamena) for clinical samples and data as well as the PAFIP members (Marga Corredera) for the data collection. This work was supported by: SAF2016-76046-R and SAF2013-46292-R (MINECO and FEDER) to B.C.F., PI16/ 00156 (isciii and FEDER) to J.P.V., LUCHAMOS POR LA VIDA project to F.R.J. and J.P.V., SAF2017-83702-R (MINECO and FEDER), Red TERCEL RD12/0019/0024 (ISCIII) and GVA-PROMETEO 2018/041 (Generalitat Valenciana) to S.M. J.P.V. is 
supported by the RyC research programme (RYC-2013-14097) and F.R.J. by the predoctoral research programme (BES-2014-070615), from MINECO and FEDER.

\begin{abstract}
Author details
'Department of Psychiatry, University Hospital Marqués de Valdecilla-IDIVAL, Santander 39011 Cantabria, Spain. ${ }^{2}$ Department of Molecular Biology, School of Medicine, University of Cantabria, Santander 39011 Cantabria, Spain. ${ }^{3}$ Centro de Investigación Biomédica en Red de Salud Mental (CIBERSAM), Instituto de Salud Carlos III, Madrid 28029, Spain. ${ }^{4}$ Instituto de Neurociencias, UMH-CSIC, Alicante 3550, Spain. ${ }^{5}$ Instituto de Biomedicina y Biotecnología de Cantabria, IBBTEC (Universidad de Cantabria, CSIC, SODERCAN), 39011 Santander, Cantabria, Spain. ${ }^{6}$ Department of Physiology and Pharmacology, School of Medicine, University of Cantabria, Santander 39011 Cantabria, Spain. 'Infection, Immunity and Digestive Pathology Group, University Hospital Marqués de Valdecilla-IDIVAL, Santander 39011 Cantabria, Spain. ${ }^{8}$ Department of Psychiatry, Sierrallana Hospital, Torrelavega 39300 Cantabria, Spain. ${ }^{9}$ Institute of Parasitology and Biomedicine "López-Neyra" (IPBLN-CSIC), Armilla 18016 Granada, Spain. ${ }^{10}$ Department of Molecular Biology, Centro de Biología Molecular "Severo Ochoa" (UAM-CSIC), Universidad Autónoma de Madrid, Madrid 28049, Spain. ${ }^{11}$ Centro de Investigación Biomédica en Red de Enfermedades Cardiovasculares (CIBERCV), Instituto de Salud Carlos III, Madrid 28029, Spain. ${ }^{12}$ Department of Pharmacology, University of the Basque Country UPV/EHU, Leioa 48940 Bizkaia, Spain. ${ }^{13}$ Department of Physiology and Biophysics, Virginia Commonwealth University School of Medicine, P. O. Box 980551 Molecular Medicine Research Building 5-038, Richmond 23298 Virginia, USA. ${ }^{14}$ Department of Psychiatry, School of Medicine, University Hospital Virgen del Rocio-IBiS, Sevilla 41013, Spain
\end{abstract}

\section{Conflict of interest}

The authors declare that they have no conflict of interest.

\section{Publisher's note}

Springer Nature remains neutral with regard to jurisdictional claims in published maps and institutional affiliations.

Supplementary Information accompanies this paper at (https://doi.org/ 10.1038/s41398-019-0647-7).

Received: 8 May 2019 Revised: 8 October 2019 Accepted: 20 October 2019 Published online: 18 November 2019

\section{References}

1. Chouinard, G. et al. Antipsychotic-induced dopamine supersensitivity psychosis: pharmacology, criteria, and therapy. Psychother. Psychosom. 86, 189-219 (2017).

2. Seeman, P. Targeting the dopamine D2 receptor in schizophrenia. Expert Opin. Ther. Targets 10, 515-531 (2006).

3. Rampino, A. et al. Antipsychotic drug responsiveness and dopamine receptor signaling; old players and new prospects. Front. Psychiatry 9, 702 (2018).

4. Aringhieri, S. et al. Molecular targets of atypical antipsychotics: from mechanism of action to clinical differences. Pharm. Ther. 192, 20-41 (2018).

5. Fusar-Poli, P. et al. Treatments of negative symptoms in schizophrenia: metaanalysis of 168 randomized placebo-controlled trials. Schizophr. Bull. 41, 892-899 (2015).

6. Meltzer, H. Y. Treatment-resistant schizophrenia-the role of clozapine. Curr. Med. Res. Opin. 14, 1-20 (1997)

7. Elkis, H. Treatment-resistant schizophrenia. Psychiatr. Clin. North Am. 30 , 511-533 (2007).

8. Gillespie, A. L., Samanaite, R., Mill, J., Egerton, A. \& MacCabe, J. H. Is treatmentresistant schizophrenia categorically distinct from treatment-responsive schizophrenia? a systematic review. BMC Psychiatry 17, 12 (2017).

9. Stone, J. M. Glutamatergic antipsychotic drugs: a new dawn in the treatment of schizophrenia? Ther. Adv. Psychopharmacol. 1, 5-18 (2011).

10. Nordstrom, A. L. et al. D1, D2, and 5-HT2 receptor occupancy in relation to clozapine serum concentration: a PET study of schizophrenic patients. Am. J. Psychiatry 152, 1444-1449 (1995).
11. Miller, R. Mechanisms of action of antipsychotic drugs of different classes, refractoriness to therapeutic effects of classical neuroleptics, and individual variation in sensitivity to their actions: Part I. Curr. Neuropharmacol. 7, 302-314 (2009).

12. Wisler, J. W., Xiao, K., Thomsen, A. R. \& Lefkowitz, R. J. Recent developments in biased agonism. Curr. Opin. Cell Biol. 27, 18-24 (2014).

13. Wang, H., Farhan, M., Xu, J., Lazarovici, P. \& Zheng, W. The involvement of DARPP-32 in the pathophysiology of schizophrenia. Oncotarget $\mathbf{8}$, 53791-53803 (2017)

14. Nishi, A. et al. Glutamate counteracts dopamine/PKA signaling via dephosphorylation of DARPP-32 Ser-97 and alteration of its cytonuclear distribution. J. Biol. Chem. 292, 1462-1476 (2017).

15. Nicoletti, F., Bruno, V., Ngomba, R. T., Gradini, R. \& Battaglia, G. Metabotropic glutamate receptors as drug targets: what's new? Curr. Opin. Pharm. 20, 89-94 (2015).

16. Sainz, J. et al. Inflammatory and immune response genes have significantly altered expression in schizophrenia. Mol. Psychiatry 18, 1056-1057 (2013).

17. Crespo-Facorro B., Prieto C., Sainz J. Schizophrenia gene expression profile reverted to normal levels by antipsychotics. Int. J. Neuropsychopharmacol. 18, pii: pyu066 (2014).

18. Pelayo-Teran, J. M. et al. Epidemiological factors associated with treated incidence of first-episode non-affective psychosis in Cantabria: insights from the Clinical Programme on Early Phases of Psychosis. Early Inter. Psychiatry 2, 178-187 (2008).

19. Llerena, S. et al. Applied diagnostics in liver cancer. Efficient combinations of sorafenib with targeted inhibitors blocking AKT/mTOR. Oncotarget 9, 30869-30882 (2018).

20. Zhang H., Nielsen A. L., Stromgaard K. Recent achievements in developing selective Gq inhibitors. Med. Res. Rev. 1-23 (2019).

21. Phillipson, O. T. Afferent projections to the ventral tegmental area of Tsai and interfascicular nucleus: a horseradish peroxidase study in the rat. J. Comp. Neurol. 187, 117-143 (1979).

22. Khlghatyan J., Quintana C., Parent M., Beaulieu J. M. High sensitivity mapping of cortical dopamine D2 receptor expressing neurons. Cereb. Cortex $\mathbf{2 9}$ 3813-3827 (2018)

23. Lopez-Gimenez, J. F. et al. Validation of schizophrenia gene expression profile in a preclinical model of maternal infection during pregnancy. Schizophr. Res. 189, 217-218 (2017).

24. Khokhar, J. Y., Henricks, A. M., Sullivan, E. D. K. \& Green, A. I. Unique effects of clozapine: a pharmacological perspective. Adv. Pharm. 82, 137-162 (2018).

25. Rice, M. W., Roberts, R. C., Melendez-Ferro, M. \& Perez-Costas, E. Mapping dopaminergic deficiencies in the substantia nigra/ventral tegmental area in schizophrenia. Brain Struct. Funct. 221, 185-201 (2016).

26. Howes, O. D. \& Kapur, S. The dopamine hypothesis of schizophrenia: version III-the final common pathway. Schizophr. Bull. 35, 549-562 (2009).

27. Kapur, S., Zipursky, R., Jones, C., Remington, G. \& Houle, S. Relationship between dopamine $\mathrm{D}(2)$ occupancy, clinical response, and side effects: a double-blind PET study of first-episode schizophrenia. Am. J. Psychiatry 157, 514-520 (2000).

28. Mead, T. J. \& Apte, S. S. ADAMTS proteins in human disorders. Matrix Biol. 7172, 225-239 (2018).

29. Kelwick, R., Desanlis, I., Wheeler, G. N. \& Edwards, D. R. The ADAMTS (a disintegrin and metalloproteinase with thrombospondin motifs) family. Genome Biol. 16, 113 (2015).

30. Colige, A. et al. Domains and maturation processes that regulate the activity of ADAMTS-2, a metalloproteinase cleaving the aminopropeptide of fibrillar procollagens types I-III and V. J. Biol. Chem. 280, 34397-34408 (2005).

31. Bekhouche, M. et al. Determination of the substrate repertoire of ADAMTS2, 3, and 14 significantly broadens their functions and identifies extracellular matrix organization and TGF-beta signaling as primary targets. FASEB J. 30, 1741-1756 (2016).

32. Berretta, S. Extracellular matrix abnormalities in schizophrenia. Neuropharmacology 62, 1584-1597 (2012).

33. Benes, F. M. et al. Regulation of the GABA cell phenotype in hippocampus of schizophrenics and bipolars. Proc. Natl Acad. Sci. USA 104, 10164-10169 (2007).

34. Hoseth, E. Z. et al. Exploring the Wnt signaling pathway in schizophrenia and bipolar disorder. Transl. Psychiatry 8, 55 (2018).

35. Pietersen, C. Y. et al. Molecular profiles of parvalbumin-immunoreactive neurons in the superior temporal cortex in schizophrenia. J. Neurogenet. $\mathbf{2 8 ,} 70-85$ (2014). 
36. Pietersen, C. Y. et al. Molecular profiles of pyramidal neurons in the superior temporal cortex in schizophrenia. J. Neurogenet. 28, 53-69 (2014).

37. Miller, R. Mechanisms of action of antipsychotic drugs of different classes, refractoriness to therapeutic effects of classical neuroleptics, and individual variation in sensitivity to their actions: Part II. Curr. Neuropharmacol. 7, 315-330 (2009).

38. Paul, M. L., Graybiel, A. M., David, J. C. \& Robertson, H. A. D1-like and D2-like dopamine receptors synergistically activate rotation and c-fos expression in the dopamine-depleted striatum in a rat model of Parkinson's disease. $J$. Neurosci. 12, 3729-3742 (1992).

39. Belgacem, Y. H. \& Borodinsky, L. N. CREB at the crossroads of activitydependent regulation of nervous system development and function. Adv. Exp. Med. Biol. 1015, 19-39 (2017).

40. Carlezon, W. A. Jr., Duman, R. S. \& Nestler, E. J. The many faces of CREB. Trends Neurosci. 28, 436-445 (2005).

41. Lonze, B. E. \& Ginty, D. D. Function and regulation of CREB family transcription factors in the nervous system. Neuron 35, 605-623 (2002).

42. Aringhieri, $\mathrm{S}$. et al. Clozapine as the most efficacious antipsychotic for activating ERK 1/2 kinases: role of 5-HT2A receptor agonism. Eur. Neuropsychopharmacol. 27, 383-398 (2017).
43. Schmid, C. L., Streicher, J. M., Meltzer, H. Y. \& Bohn, L. M. Clozapine acts as an agonist at serotonin 2A receptors to counter MK-801-induced behaviors through a betaarrestin2-independent activation of Akt. Neuropsychopharmacology 39, 1902-1913 (2014)

44. Lukasiewicz, S., Faron-Gorecka, A., Kedracka-Krok, S. \& Dziedzicka-Wasylewska, $M$. Effect of clozapine on the dimerization of serotonin 5-HT(2A) receptor and its genetic variant 5-HT(2A)H425Y with dopamine D(2) receptor. Eur. J. Pharm. 659, 114-123 (2011).

45. Wang, H., Xu, J., Lazarovici, P., Quirion, R. \& Zheng, W. cAMP response element-binding protein (CREB): a possible signaling molecule link in the pathophysiology of schizophrenia. Front. Mol. Neurosci. 11, 255 (2018).

46. Seamon, K. B., Padgett, W. \& Daly, J. W. Forskolin: unique diterpene activator of adenylate cyclase in membranes and in intact cells. Proc. Natl Acad. Sci. USA 78, 3363-3367 (1981)

47. Zhang, G., Liu, Y., Ruoho, A. E. \& Hurley, J. H. Structure of the adenylyl cyclase catalytic core. Nature 386, 247-253 (1997).

48. Del'guidice, T., Lemasson, M. \& Beaulieu, J. M. Role of beta-arrestin 2 downstream of dopamine receptors in the basal ganglia. Front. Neuroanat. 5, 58 (2011). 